\title{
Evidence for Serpulina hyodysenteriae being recombinant, with an epidemic population structure
}

\author{
Darren J. Trott, Sophy L. Oxberry and David J. Hampson \\ Author for correspondence: David J. Hampson. Tel: +61 89360 2287. Fax: +61 893104144. \\ e-mail: hampson@numbat.murdoch.edu.au
}

Division of Veterinary and Biomedical Sciences, Murdoch University, Murdoch, WA 6150, Australia

\begin{abstract}
The population structure of Serpulina hyodysenteriae was investigated using multilocus enzyme electrophoresis. A total of 231 isolates were divided into $\mathbf{5 0}$ electrophoretic types (ETs), with a mean genetic diversity of 0.29 for the number of ETs and $\mathbf{0 . 2 3}$ for the number of isolates. Subsets of isolates from two Australian states (71 isolates from Victoria and 68 isolates from Queensland) exhibited as much genetic variation as the entire collection. The calculated index of association $\left(I_{A}\right)$ for the number of ETs $(0.29 \pm 0.17)$ was not significantly different from zero, and hence provided evidence for the occurrence of significant genetic recombination accounting for the observed variation between strains. In contrast, the $I_{A}$ for the number of isolates (3.93 \pm 0.03$)$ was significantly different from zero, with seven of the 50 ETs (ETs $4,6,13,14,20,33$ and 35 ) containing $51 \%$ of all the isolates. Even when multiple isolates from the same farm were removed from the analysis, the $I_{A}$ value for the number of isolates remained significantly greater than zero $\left(I_{A}\right.$ $9 \cdot 87 \pm 0.04)$, indicating that it was not biased by their inclusion. The results suggest that $\mathrm{S}$. hyodysenteriae has an epidemic population structure.
\end{abstract}

Keywords: Serpulina byodysenteriae, population structure, index of association, multilocus enzyme electrophoresis

\section{INTRODUCTION}

The intestinal spirochaete Serpulina byodysenteriae is the aetiologic agent of swine dysentery (SD), a severe mucohaemorrhagic diarrhoeal disease of pigs (Stanton, 1992). S. byodysenteriae also naturally infects rheas (Jensen et al., 1996), and will colonize a range of experimentally infected animals, including mice (Joens \& Glock, 1979), guinea pigs (Joens et al., 1978) and chicks (Sueyoshi \& Adachi, 1990). In Australia, SD has been considered to be the most serious productionlimiting endemic disease of pigs (Cutler \& Gardner, 1988). Many aspects of the causative organism remain unknown or are incompletely characterized, particularly its genetic structure, gene organization and regulation, its pathogenesis, and the immune response to its presence in the host (ter Huurne \& Gaastra, 1995). Control measures for SD are expensive and have been hindered by the lack of an economical vaccine that is protective against all strains of the organism (e.g. Fernie

Abbreviations: ET, electrophoretic type; $I_{A}$ index of association; MLEE, multilocus enzyme electrophoresis; SD, swine dysentery. et al., 1983; Lysons et al., 1987). Immunity against SD is serotype specific (Joens et al., 1983). The serogrouping system devised for S. byodysenteriae is based upon the immunoreactivity of hyperimmune rabbit sera raised against LPS antigens in agarose gel double-diffusion tests (Baum \& Joens, 1979; Hampson et al., 1989). In our laboratory, 11 specific serostrains representative of each serogroup (A-K) are recognized, with multiple serovars recognized in some of the serogroups (Lau \& Hampson, 1992; Hampson et al., 1997).

Strain diversity in S. byodysenteriae has been investigated using restriction endonuclease analysis (Combs et al., 1989, 1992; Harel et al., 1994; ter Huurne et al., 1992a) and random amplification of polymorphic DNA analysis (Dugourd et al., 1996), with considerable genetic diversity being identified. Multilocus enzyme electrophoresis (MLEE) has also been used to investigate diversity amongst 99 isolates of $S$. hyodysenteriae, and identified 29 electrophoretic types (ETs) divided into four genetic divisions (Lee et al., 1993a). In that study, the population structure was thought to be clonal; however, only a small number of isolates was examined 
and no attempt was made to calculate the index of association $\left(I_{\mathrm{A}}\right)$, a convenient measure of the degree of linkage disequilibrium operating in a population (Maynard Smith et al., 1993). The $I_{\mathrm{A}}$ is calculated on the basis of the distribution of allelic mismatches between pairs of isolates, ETs or clonal groups among all loci, and is expressed as the ratio of variance observed in mismatches $\left(V_{0}\right)$ to variance expected at linkage equilibrium $\left(V_{\mathrm{e}}\right)$, where $I_{\mathrm{A}}=V_{\mathrm{o}} / V_{\mathrm{e}}-1$ (Maynard Smith et al., 1993). Measurements that are significantly different from zero indicate clonality (i.e. the population structure is approaching linkage disequilibrium caused by the non-random association of alleles that have arisen largely through ancestral genetic mutations), whereas those that are not significantly different from zero indicate that recombination is common in the species (i.e. random association of alleles in the population has been caused by rapid recombination, disrupting any linkage disequilibrium). The majority of bacterial species are clonal; however, some, including the important human pathogen Neisseria gonorrboeae, have been shown to have a recombinant population structure (Maynard Smith et al., 1993). Others such as the closely related Neisseria meningitidis superficially appear to be clonal (i.e. the $I_{\mathrm{A}}$ value for the number of isolates examined is significantly different from zero) but have significant underlying rates of recombination that have shaped the population structure (i.e. the $I_{\mathrm{A}}$ value for the number of ETs examined is not significantly different from zero). Such populations are said to have an epidemic population structure, with certain common clonal groups with selective advantage emerging to dominate the overall recombinant population (Maiden \& Feavers, 1995).

In addition to the previous MLEE study of porcine isolates (Lee et al., 1993a), we also have shown by MLEE that four S. hyodysenteriae strains isolated from rheas were closely related to or shared the same ET as certain porcine strains of the species (Trott et al., 1996). In the present study, we have extended our previous observations by examining a further 128 porcine $S$. byodysenteriae isolates at the same 15 enzyme loci used previously (Lee et al., 1993a). These included reference strains from the USA and Canada, and field isolates from Australia, the UK and the Netherlands. Our major aims were to analyse a large collection of isolates to discover the extent of genetic diversity and distribution of haplotypes in S. hyodysenteriae, and to use the MLEE data to calculate the $I_{\mathrm{A}}$ value, and hence to provide insight into genetic factors underlying the population structure of the species.

\section{METHODS}

Bacterial isolates. The strain designation, origin and serotype (where known) of each of the 231 S. hyodysenteriae isolates used in this study may be obtained by contacting the author for correspondence. All isolates were obtained in pure culture from the collection held at the Australian Reference Laboratory for Intestinal Spirochaetes, Murdoch University, Perth, Western Australia. One hundred and three of the isolates have been analysed previously by MLEE (Lee $e t$ al., 1993a ; Trott $e$ t al., 1996). Isolates were from pigs, except for four isolated from rheas with necrotizing typhlitis (Jensen $e t$ al., 1996). One hundred and ninety isolates were from Australian field cases of SD submitted between 1986 and 1996. These included 71 isolates from Victoria, 68 from Queensland, 26 from Western Australia, 15 from New South Wales, six from South Australia, and four from Tasmania. The remaining 41 isolates included 14 from the UK (including serostrains A1, P35/2, MC52/80, KF9 and the non-virulent strain VS1), 12 from the USA (including reference strains B204, B78 ${ }^{\mathrm{T}}$ and B234 and serostrains B6933, B8044 and Ack 300/8), 11 field isolates from the Netherlands, three serostrains from Canada (B169, FM88-90, FMV89.3323), and a single field isolate from South Korea.

The isolates in the collection had previously been confirmed as being $S$. hyodysenteriae by their strong $\beta$-haemolysis on blood agar, production of indole, and their positive reactivity in a PCR test based upon a cloned DNA sequence shown to be specific for S. hyodysenteriae (Atyeo et al., 1996a). One hundred and sixty-five isolates $(71.4 \%)$ had been serotyped by the method of Lau \& Hampson (1992) and allocated to the 11 serogroups defined by Hampson et al. (1997).

Culture conditions. Stock cultures held at $-80^{\circ} \mathrm{C}$ were thawed and inoculated into $7 \mathrm{ml}$ Kunkle's anaerobic broth medium (Kunkle et al., 1986), incubated at $37^{\circ} \mathrm{C}$ on a rocking platform for 72-96 h, transferred into $250 \mathrm{ml}$ Kunkle's medium and again incubated at $37^{\circ} \mathrm{C}$ on a rocking platform for $72-96 \mathrm{~h}$. After reaching mid-exponential phase $\left(10^{8}-10^{9}\right.$ cells $\left.\mathrm{ml}^{-1}\right)$, cultures were centrifuged $\left(10000 \mathrm{~g}, 4^{\circ} \mathrm{C}, 20 \mathrm{~min}\right)$, washed in sterile PBS, $\mathrm{pH} 7 \cdot 2,0 \cdot 15 \mathrm{M}$, and centrifuged again $\left(10000 \mathrm{~g}, 4^{\circ} \mathrm{C}, 20 \mathrm{~min}\right)$. The resulting pellet was suspended in 5 vols sterile distilled water for MLEE analysis.

MLEE. The methods used for cell preparation, buffers, enzyme systems and running conditions for MLEE analysis were as previously described (Selander et al., 1986; Lymbery et al., 1990; Lee et al., 1993a). Briefly, the suspended pellet was sonicated for two $30 \mathrm{~s}$ cycles on ice using a Branson B30 sonifier, centrifuged at $20000 \mathrm{~g}$ for $20 \mathrm{~min}$ and the supernatant was extracted and immediately used for electrophoresis in horizontal starch gels as described by Selander et al. (1986). The allelic profiles of 15 constitutive enzyme loci were examined (Lee et al., 1993a): acid phosphatase, alcohol dehydrogenase, hexokinase and nucleoside phosphorylase were assayed using a Tris/maleate $(\mathrm{pH} \mathrm{7.4)} \mathrm{buffer}$ system; alkaline phosphatase, phosphoglucose isomerase, guanine deaminase and mannose phosphate isomerase were assayed using a phosphate ( $\mathrm{pH} 7$ ) buffer system ; esterase, fructose-1,6diphosphatase, L-leucyl-glycyl-glycine peptidase, phosphoglucomutase and superoxide dismutase were assayed using a discontinuous buffer system (Tris/citrate gel buffer, LiOH electrode buffer); and arginine phosphokinase and glutamate dehydrogenase were assayed using a discontinuous buffer system (Tris/citrate gel buffer, borate electrode buffer). The variation in the mobility of an enzyme was interpreted as the products of different alleles at a specific locus encoding that enzyme. Distinctive mobility variants were numbered in order of decreasing rate of anodal migration, except for acid phosphatase allele 8 , which appeared directly above allele 1 . Isolates with identical enzymic profiles at all loci were grouped into an ET. ETs obtained for the new isolates were directly compared with standards obtained in the previous MLEE studies (Lee et al., 1993a; Trott et al., 1996) using the same numbering system for allele designation. The numbering system has been used to characterize other intestinal spiro- 


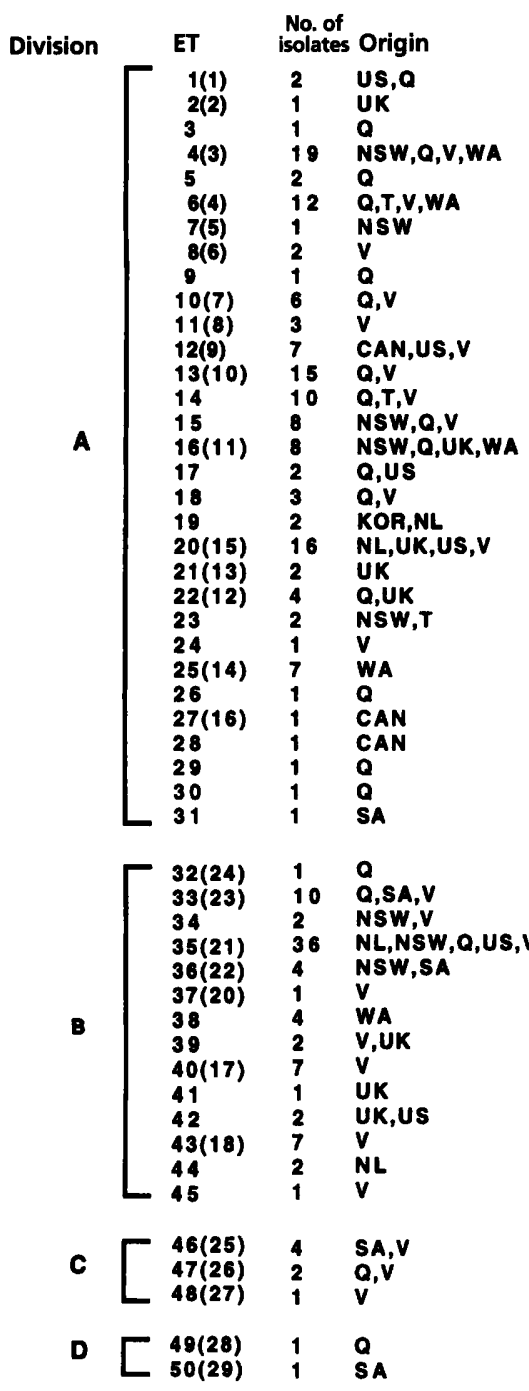

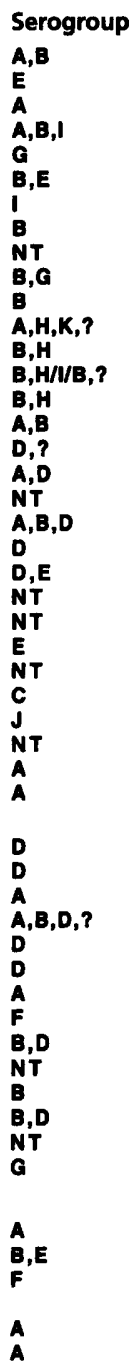
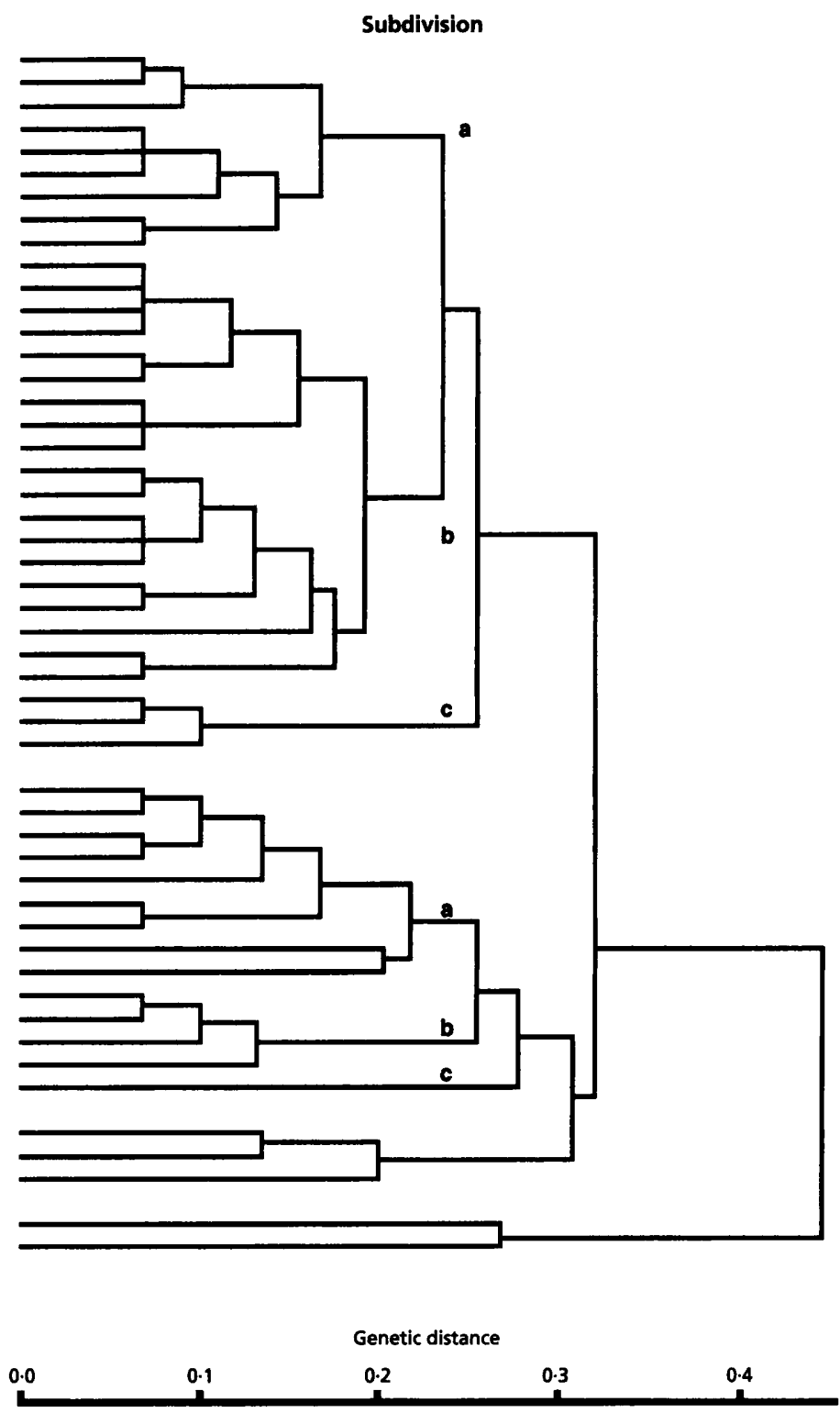

Fig. 1. Phenogram depicting relationships between 231 isolates of $S$. hyodysenteriae analysed by MLEE. The phenogram is divided into four divisions, with divisions A and B comprising three subdivisions, and 50 ETs. The old ETs (1-29) of Lee et al. (1993a) are indicated in parentheses. The number of isolates in each ET, the origin of the isolates and their serotype where known are also indicated. Additional information such as the strain designation of each isolate, and the allele profiles of each ET is available from the corresponding author upon request. The unweighted paired group method of arithmetic means was used to construct the phenogram. CAN, Canada; KOR, Korea; NL, The Netherlands; NSW, New South Wales; Q, Queensland; SA, South Australia; T, Tasmania; UK, United Kingdom; US, United States; V, Victoria; WA, Western Australia. Serogroups A-K, serotyping system according to Hampson et al. (1997); NT, not tested; ?, not typable.

chaete species (Lee et al., 1993b, c; Lee \& Hampson, 1994) and thus is not completely sequential for $S$. byodysenteriae. Gel runs were repeated up to six times to ensure the correct allele designation.

Statistical analysis. Genetic diversity $(b)$, a measure of the amount of allelic variation at each enzyme locus, was calculated for both the number of ETs and the number of isolates as $b=\left(1-\Sigma P_{1}^{2}\right)[n /(n-1)]$, where $P_{1}$ is the frequency of the indicated allele and $n$ the number of ETs or isolates (Nei, 1977). Comparison of the genetic diversities generated using either the number of ETs or the number of isolates is a convenient indicator of the influence that isolate distribution into ETs has on the overall genetic diversity. Haplotypic diversity $(H)$, a measure of the frequency of haplotypes within the population (the term haplotype referring to a set of haploid organisms sharing a common set of alleles and belonging to the same ET), was calculated as $H=1-\Sigma P^{2}$, where $P_{j}$ is the frequency of the $j$ th haplotype (Fuste et al., 1996). Genetic distance between ETs was calculated by pairwise comparison as the proportions of loci at which dissimilar alleles occurred. A phenogram was generated to illustrate the genetic relationships between ETs using the unweighted pair group method of arithmetic means clustering 
fusion strategy (Burr, 1968, 1970). The $I_{\mathrm{A}}$, an indicator of the degree of linkage disequilibrium operating in the population, was calculated according to the measurement devised by Maynard Smith et al. (1993).

\section{RESULTS}

\section{MLEE genetic relationships between isolates}

The 231 S. byodysenteriae isolates were divided into 50 ETs depicted as a phenogram in Fig. 1. The phenogram was divided into four major divisions: division A (ETs 1-31), division B (ETs 32-45), division C (ETs 46-48) and division D (ETs 49-50). Divisions $B$ and $C$ were separated by a genetic distance of $0 \cdot 30$, division $A$ was separated from $B$ and $C$ by a genetic distance of 0.32 , and division $D$ was separated from $A, B$ and $C$ by a genetic distance of 0.4 . The divisions roughly approximate those of Lee et al. (1993a) but include more ETs. The majority of ETs contained one to eight isolates; the exceptions were ET 4 (19 isolates), ET 6 (11 isolates), ET 13 (15 isolates), ET 14 (10 isolates), ET 20 (15 isolates), ET 33 (10 isolates) and ET 35 (36 isolates). The isolates from farmed rheas were located in ETs 15 (two isolates), 17 and 20 , all of which also contained porcine isolates.

\section{Statistical analysis}

The mean number of alleles per locus was $2 \cdot 7$ : three of the loci (alcohol dehydrogenase, esterase and superoxide dismutase) were monomorphic and the remaining 12 were polymorphic. Isolates yielded reproducible banding patterns, except for two (VS1 and VIC79) which had null alleles for the enzyme L-leucyl-glycyl-glycine peptidase. The mean genetic diversity per locus was 0.29 based on the number of ETs and 0.23 based on the number of isolates (Table 1 ). The mean genetic distance per locus was $0 \cdot 14$. Haplotypic diversity was calculated as 0.94 . The $I_{\mathrm{A}}$ was calculated to be $3.94 \pm 0.03$ using the number of isolates, and $0 \cdot 29 \pm 0 \cdot 176$ using the number of ETs. The $I_{\mathrm{A}}$ for the number of isolates was significantly different from zero $(P<0.05)$, whilst the $I_{\mathrm{A}}$ for the number of ETs was not significantly different from zero. The results are consistent with the epidemic model of population structure described by Maynard Smith $e t$ al. (1993). When isolates that were located in the same ET and obtained from the same piggery, or from piggeries with known movements of pigs between them, were removed from the $I_{\mathrm{A}}$ calculation to leave just one representative from each piggery, the $I_{\mathrm{A}}$ value for the number of isolates was still significantly different from zero $\left(I_{\mathrm{A}} 9.87 \pm 0.04\right)$.

\section{Geographical distribution}

Seven of the 15 ETs which contained non-Australian field isolates and reference strains also contained isolates from Australia. These included ETs 20 and 35, which both contained isolates from the Netherlands and the USA. Of the 21 ETs that contained more than one

Table 1. Allele frequencies and genetic diversities ( $h$; mean genetic diversity 0.288 ) calculated using $n=$ number of ETs at 15 enzyme loci analysed for 231 S. hyodysenteriae isolates divided into $50 \mathrm{ETS}$

\begin{tabular}{|c|c|c|c|c|c|c|c|c|c|c|}
\hline \multirow[t]{2}{*}{ Enzyme* } & \multicolumn{9}{|c|}{ Frequency of the indicated allele } & \multirow[t]{2}{*}{$\boldsymbol{h}$} \\
\hline & 0 & 1 & 2 & 3 & 4 & 5 & 6 & 7 & 8 & \\
\hline MPI & 0.000 & 0.000 & 0.220 & 0.080 & $0 \cdot 100$ & 0.420 & 0.060 & $0 \cdot 120$ & 0.000 & 0.756 \\
\hline NP & 0.000 & 0.000 & 0.360 & 0.360 & 0.000 & 0.000 & 0.100 & 0.000 & 0.000 & 0.746 \\
\hline LGG & 0.020 & 0.340 & 0.600 & 0.040 & 0.000 & 0.000 & 0.000 & 0.000 & 0.000 & 0.533 \\
\hline HK & 0.000 & 0.000 & 0.000 & 0.700 & 0.080 & 0.220 & 0.000 & 0.000 & 0.000 & 0.464 \\
\hline PGI & 0.000 & 0.000 & 0.000 & 0.340 & 0.000 & 0.660 & 0.000 & 0.000 & 0.000 & 0.458 \\
\hline $\mathrm{ACP}$ & 0.000 & 0.740 & $0 \cdot 180$ & 0.000 & 0.000 & 0.040 & 0.000 & 0.000 & 0.040 & 0.425 \\
\hline GDA & 0.000 & 0.760 & $0 \cdot 100$ & 0.140 & 0.000 & 0.000 & 0.000 & 0.000 & 0.000 & 0.401 \\
\hline $\mathrm{GDH}$ & 0.000 & 0.020 & 0.920 & 0.060 & 0.000 & 0.000 & 0.000 & 0.000 & 0.000 & $0 \cdot 153$ \\
\hline FDP & 0.000 & $0 \cdot 020$ & 0.000 & 0.920 & 0.060 & 0.000 & 0.000 & 0.000 & 0.000 & $0 \cdot 153$ \\
\hline ALP & 0.000 & 0.060 & 0.000 & 0.940 & 0.000 & 0.000 & 0.000 & 0.000 & 0.000 & 0.115 \\
\hline $\mathrm{AK}$ & 0.000 & 0.960 & 0.040 & 0.000 & 0.000 & 0.000 & 0.000 & 0.000 & 0.000 & 0.078 \\
\hline $\mathrm{ADH}$ & 0.000 & 0.000 & 0.980 & 0.000 & 0.020 & 0.000 & 0.000 & 0.000 & 0.000 & 0.040 \\
\hline PGM & 0.000 & 0.000 & 0.000 & 1.000 & 0.000 & 0.000 & 0.000 & 0.000 & 0.000 & 0.000 \\
\hline EST & 0.000 & 0.000 & 0.000 & 0.000 & 1.000 & 0.000 & 0.000 & 0.000 & 0.000 & 0.000 \\
\hline SOD & 0.000 & 0.000 & 1.000 & 0.000 & 0.000 & 0.000 & 0.000 & 0.000 & 0.000 & 0.000 \\
\hline
\end{tabular}

* MPI, mannose phosphate isomerase; NP, nucleoside phosphorylase; LGG, L-leucyl-glycyl-glycine peptidase; HK, hexokinase; PGI, phosphoglucose isomerase; ACP, acid phosphatase; GDA, guanine deaminase; GDH, glutamate dehydrogenase; FDP, fructose-1,6-diphosphatase; ALP, alkaline phosphatase; AK, arginine phosphokinase; $\mathrm{ADH}$, alcohol dehydrogenase; PGM, phosphoglucomutase; EST, esterase; SOD, superoxide dismutase. 
Table 2. Ratio of isolates to ETs and genetic diversity (GD) according to isolate origin

\begin{tabular}{|lcccc|}
\hline Origin & $\begin{array}{c}\text { No. of } \\
\text { isolates }\end{array}$ & $\begin{array}{c}\text { No. of } \\
\text { ETs }\end{array}$ & $\begin{array}{c}\text { Ratio of } \\
\text { isolates: ETs }\end{array}$ & GD \\
\hline Australian isolates & & & & \\
Queensland & 68 & 22 & $3 \cdot 09$ & $0 \cdot 25$ \\
Victoria & 71 & 5 & $3 \cdot 09$ & $0 \cdot 27$ \\
Western Australia & 26 & 9 & $5 \cdot 20$ & NT \\
New South Wales & 15 & 5 & $1 \cdot 67$ & NT \\
South Australia & 6 & 3 & $1 \cdot 20$ & NT \\
Tasmania & 4 & 43 & $1 \cdot 33$ & NT \\
Total & 190 & & $4 \cdot 42$ & $0 \cdot 28$ \\
Non-Australian isolates & & 8 & & \\
UK & 14 & 6 & $2 \cdot 75$ & NT \\
USA & 12 & 4 & $2 \cdot 75$ & NT \\
Netherlands & 11 & 3 & $1 \cdot 00$ & NT \\
Canada & 3 & 1 & $1 \cdot 00$ & NT \\
Korea & 1 & 15 & $2 \cdot 73$ & NT \\
Total & 41 & 50 & $4 \cdot 62$ & $0 \cdot 29$ \\
Combined total & 231 & & & \\
\hline
\end{tabular}

NT, Not tested.

Australian isolate, 15 contained isolates from more than one Australian state. No genetic clustering of isolates according to their place of origin was evident. The ratio of isolates to ETs for each of the geographical regions is shown in Table 2. The majority of the isolates were from Victoria and Queensland, and the isolate:ET ratio (3.09) and genetic diversity (0.25-0.27) obtained for each of these subpopulations were identical. The genetic diversities were very similar to the value obtained for the entire collection $(0 \cdot 29)$.

\section{Serogroup distribution}

Division A contained representatives of 10 of the 11 recognized serogroups. Divisions B, C and D contained isolates belonging to six serogroups. Isolates belonging to the most commonly occurring serogroups in Australia, A, B, D, G and E (Hampson et al., 1994), were located in both divisions $A$ and $B$. Isolates of serogroups $\mathrm{C}, \mathrm{H}, \mathrm{I}, \mathrm{J}$ and $\mathrm{K}$ were restricted to division $\mathrm{A}$, and serogroup $\mathrm{F}$ to divisions $\mathrm{B}$ and $\mathrm{C}$. Of the $23 \mathrm{ET}$ s that contained more than one isolate which had been serotyped, 16 were represented by more than one serogroup, including six of the seven ETs that contained 10 or more isolates.

\section{Distribution of avirulent strains}

Three strains that were known to be avirulent in pigs, strains B78 ${ }^{\mathrm{T}}$ (Jensen \& Stanton, 1993), VS1 (Burrows \& Lemcke, 1981) and SA3 (Lee et al., 1993a), were genetically distinct from one another, being located in ETs 12,39 and 50, respectively.

\section{DISCUSSION}

The spirochaetes represent a distinct branch of bacterial evolution (Woese, 1987) and the heterogeneity of the group is reflected in the wide range of the $\mathrm{mol} \% \mathrm{G}+\mathrm{C}$ values for each genus $(24-65 \%)$ (Baranton \& Old, 1995). The Serpulina/Brachyspira cluster represents a deep branch of the spirochaete 16S rRNA phylogenetic tree, and the species that have been identified within the cluster are separated by very small $16 \mathrm{~S}$ rRNA DNA sequence differences (Hookey et al., 1994; Pettersson et al., 1996; Stanton et al., 1996), suggesting that speciation in the cluster is a relatively recent phenomenon. All of the known members of the genus Serpulina are gutassociated anaerobes that share common sugar fermentation pathways and NADH oxidase activity for survival in environments of low oxygen tension (Stanton, 1997). Of the five species that have been named and characterized, $S$. hyodysenteriae has been the most thoroughly studied. Recently, gene mapping of $\mathrm{B}^{\mathrm{T}} \mathrm{T}^{\mathrm{T}}$, the type strain of $S$. hyodysenteriae, showed that its genome is circular and approximately $3.2 \mathrm{bp}$ in size; however, only relatively few genes have been identified and placed on the genetic map (Zuerner \& Stanton, 1994). Electroporation/recombination experiments with $S$. byodysenteriae haemolysin, flagella and NADH oxidase genes have recently been undertaken (ter Huurne et al., 1992b; Hyatt et al., 1994; Rosey et al., 1995; Humphrey et al., 1997). The existence of mechanisms for natural gene transfer and recombination in $S$. byodysenteriae was substantiated by the discovery of a non-lytic transducing phage that is capable of packaging and transferring S. byodysenteriae genes (Humphrey et al., 1995, 1997). It is likely that the plasmids previously reported in $S$. byodysenteriae cells by Combs et al. 
(1992) are actually activated prophage. It is not known whether $S$. byodysenteriae is naturally transformable, and as yet no other potential mechanisms of genetic exchange, such as the presence of transposons and insertional elements, have been identified in the species.

In a previous study using MLEE, Lee et al. (1993a) located 99 mainly Australian isolates into 29 specific ETs, with an overall genetic diversity of 0.26 based on the number of ETs. This diversity is comparable with most species of pathogenic bacteria (Go et al., 1996). In the present study, an additional 21 ETs were identified by examining a further 132 isolates; however, the mean genetic diversity $(0.29)$ was not substantially different from the previous study (Lee et al., 1993a). The haplotypic diversity was high (0.94), indicating that the distribution of isolates was relatively even, and generally they were not over-represented in a single ET. Only one new allele (allele 8 for the enzyme acid phosphatase) was identified, and was only responsible for the generation of two additional ETs. The remainder of the new ETs were the result of different combinations of existing alleles. Two to four alleles were generated for each locus, except for mannose phosphate isomerase, in which six alleles were present. The phenogram generated in the expanded study was also similar to that of Lee et al. (1993a) in that four major genetic divisions were apparent. Division A contained the majority of ETs and isolates in both studies. In the study of Lee $e t$ al. (1993a), their ETs 28 and 29 in division D (ETs 49 and 50 located in division $\mathrm{D}$ in the present study) were genetically distinct from the remaining ETs and shared a number of unique alleles, including allele 5 for nucleoside phosphorylase and allele 2 for guanine deaminase. Interestingly, in the present study three isolates that were clustered together in division A (ETs 29,30 and 31) also had allele 5 for nucleoside phosphorylase and allele 2 for guanine deaminase, but their remaining allele profiles were similar to the other ETs in division A. The separation of ETs into divisions A-D was not associated with any particularly strong clonal grouping of loci with the same alleles, as evidenced by the lack of deep branching in the bush-like phenogram. Lee et al. (1993a) speculated that division D might represent an avirulent biological group, since it contained the non-pathogenic strain SA3. In the present study, whilst SA3 was still in division D, avirulent strain $\mathrm{B} 78^{\mathrm{T}}$ belonged to division A and VS1 to division $\mathrm{B}$. Thus, although we cannot add to the speculation concerning division $\mathrm{D}$ organisms, it appears that strains which lack virulence are genetically diverse. Strain $\mathrm{B} 78^{\mathrm{T}}$ may have lost its virulence for pigs after repeated subculture, whereas SA3 and VS1 have reduced chemotaxis towards porcine mucin (Milner \& Sellwood, 1994). It is not known whether other isolates in the collection have reduced virulence, as relatively few $S$. byodysenteriae isolates have been tested for pathogenicity in experimentally infected animals. It is likely that a number of different factors are required for full expression of $S$. hyodysenteriae virulence in pigs.

The addition of further isolates in this study also confirmed the observations of Lee et al. (1993a) that serogroups are not distributed along distinct genetic lines. Divisions A and B each contained representatives of the most common serogroups in Australia, and a substantial number of ETs contained isolates of more than one serogroup. One explanation for this is that recombination may have modified the genes involved in LPS synthesis. The possibility that recombination may have influenced the overall population structure of $S$. byodysenteriae is supported by the finding that the $I_{\mathrm{A}}$ value for the numbers of ETs $(0 \cdot 29 \pm 0 \cdot 17)$ was not significantly different from zero. This implies that genetic recombination has disrupted allelic clusters that are characteristic of a fully clonal population (Maynard Smith et al., 1993). We assume that horizontal gene flow between strains accounts for this recombination, although the possibility of genetic modification through widespread internal sequence rearrangements (via insertion sequence or transposon-like mechanisms) cannot be excluded as an explanation for the disruption of allelic clusters at this stage.

Measurements of linkage disequilibrium are best performed on large populations where the chances of geographical or sampling bias are eliminated. Ideally isolates should be obtained from a large population of freely mixing individuals where there is opportunity for genetic exchange. Reference collections provide a ready source of isolates but are usually obtained from diseased individuals who are often unrelated, and a recombinant population could still appear clonal if the sample size was not large enough to include all possible combinations. This appeared to occur in the study of Lee $e t$ al. (1993a) in which 99 isolates of $S$. byodysenteriae were examined. We calculated the $I_{\mathrm{A}}$ value for the $29 \mathrm{ETs}$ identified in that study to be $0.61 \pm 0.30$, a figure significantly different from zero, and therefore consistent with clonality in the species. As previously mentioned, ETs 28 and 29 were genetically distinct from the remaining ETs and possessed unique alleles. When these two ETs were removed from the calculation, the $I_{\mathrm{A}}$ was reduced to $0.45 \pm 0.26$, a value that was no longer significantly different from zero, and hence suggesting a recombinant population. In the present study, the identification of additional ETs meant that the inclusion of ETs 49 and 50 (ETs 28 and 29 in the previous study) in the $I_{\mathrm{A}}$ calculation did not result in the appearance of linkage disequilibrium, and the population structure was clearly recombinant.

The $I_{\mathrm{A}}$ value for the number of isolates was $3 \cdot 93 \pm 0.03$. Since some of the isolates originated from the same piggery, or from piggeries with known movement of stock, and because it is unusual for more than one strain to be present in a piggery (Combs et al., 1992), multiple isolates from the same piggery were then excluded from the $I_{\mathrm{A}}$ calculation. This resulted in the $I_{\mathrm{A}}$ value actually increasing to $9 \cdot 87 \pm 0 \cdot 04$. These results strongly suggest that as a species $S$. byodysenteriae fits the epidemic population structure model of Maynard Smith et al. (1993). In this type of structure, which was first described for the naturally transformable bacterium $N$. meningi- 
tidis, recombination has shaped the population; however, particular selected clones that have survival or virulence advantages achieve an explosive and often widespread dissemination, giving the overall appearance of clonality. In the case of $N$. meningitidis, strains of serotype A are strongly clonal and are involved in epidemic disease, whereas certain serotype $C$ strains are highly represented in small 'hyper-endemic' outbreaks amongst a background of genetically diverse recombinant strains involved in sporadic cases of meningitis (Maiden \& Feavers, 1995). Similarly, 357 isolates of Staphylococcus aureus obtained from dairy cows with mastitis were divided into $39 \mathrm{ET}$ s and had a recombinant structure; however, $90 \%$ of the isolates were restricted to eight ETs, resulting in a calculated $I_{\mathrm{A}}$ value for the number of isolates that suggested clonality (Kapur et al., 1995). The results for $S$. byodysenteriae showed that despite the operation of recombination, certain 'epidemic clones' have been widely disseminated around the globe; for instance ET 20 (15 isolates) and ET 35 (36 isolates) both contained isolates from several distinct geographical regions in the world. The overall results, however, must be interpreted in the light of possible geographical or temporal bias (i.e. the majority of isolates were obtained from Australia over a 10 year period). These do not seem to be significant factors, however, as the genetic diversities of isolates obtained from two distinct geographical regions in Australia were virtually identical, and were similar to the value obtained for the entire collection. It is possible that the isolates in the highly represented ETs may have survival advantages, such as differences in their virulence compared to the other less common strains. Alternatively they may have been disseminated artificially by relatively recent movement of pigs from infected nucleus or multiplier herds, both national and international, which have supplied pigs to production herds throughout Australia.

Other epidemiological and ecological factors associated with the disease must also be considered. Intensification of the pig industry in the last 30 years now means that pigs are kept in relatively discrete herds, with reduced opportunity for local transmission of pathogens between herds. The organism may enter a susceptible herd through the introduction of carrier pigs, and is then rapidly spread amongst non-immune stock. SD has largely been controlled by medication, destocking, thorough disinfection and limiting movements of pigs between herds (Hampson et al., 1997). We presume that these relatively recent constraints on $S$. byodysenteriae may have reduced the opportunity for strains of different genetic make-up to come into close contact, and then potentially transfer genetic material. It is likely, therefore, that the background population structure was created prior to intensification of the pig industry. This may in some way explain the epidemic population structure, with some ETs represented by large numbers of isolates because of limited opportunity for mixing. It may also be possible that less virulent strains of $S$. byodysenteriae are likely to survive for longer in infected piggeries, since they would escape detection. Similarly, in the absence of opportunities for recombination, and in the face of widespread antibiotic usage in the pig industry, strains that are more resistant to antimicrobials may become over-represented in the population.

We have recently provided evidence that Serpulina pilosicoli, a closely related intestinal spirochaete that is the agent of intestinal spirochaetosis (IS) in pigs, humans and other species, also has a recombinant population structure (D. J. Trott, A. S. J. Mikosza, B. G. Combs, S. L. Oxberry \& D. J. Hampson, unpublished). IS is a chronic endemic disease that causes a mild loss of production in pigs, and is difficult to eradicate (Taylor \& Trott, 1997). This is reflected in the population structure of the organism which approaches complete panmixis (i.e. the $I_{\mathrm{A}}$ values for both the number of ETs and the number of isolates are not significantly different from zero), a situation that is analagous with $N$. gonorrhoeae (Maynard Smith et al., 1993). We have often found up to seven genetically distinct strains of $S$. pilosicoli in a single pig herd (Atyeo et al., 1996b; D. J. Trott \& D. J. Hampson, unpublished data), giving ample opportunity for the organisms to freely recombine. The differences between the S. byodysenteriae and $S$. pilosicoli population structures may have been influenced by these epidemiological factors. S. byodysenteriae and $S$. pilosicoli are amongst the first primarily enteric pathogens that have been shown to have a recombinant population structure. Other enteric pathogens such as Escherichia coli and Salmonella spp. have been shown to be strongly clonal (Maynard Smith et al., 1993), despite the operation of genetic recombination and being under the same ecological pressure from the gastrointestinal immune system. The two species of Serpulina may have much in common with Helicobacter pylori, which also has a recombinant population structure (Go et al., 1996).

MLEE is not as sensitive for strain typing as are whole genomic techniques such as PFGE or restriction endonuclease analysis (REA), although in the study of Lee $e t$ al. (1993a) MLEE and REA results corresponded closely. Previously, we showed that rhea and porcine strains of $S$. hyodysenteriae that were located in the same ET could be differentiated by PFGE (Trott $e t$ al., 1996). The close genetic relationships of the rhea and porcine strains suggest recent crossing of host species boundaries (i.e. the rhea strains originated in pigs, or pigs were the possible source of the outbreaks of necrotizing typhlitis in farmed rheas); however, two rhea strains failed to colonize or induce disease when orally inoculated into experimental pigs, indicating that natural cross-species transmission is unlikely (Stanton et al., 1997). A more likely scenario is that the porcine and rhea strains in the same ET independently share a common set of recombinations. Given that the frequencies for alleles 2 and 3 of the enzyme nucleoside phosphorylase are identical, three of the four rhea strains had profiles that were composed of the most prevalent allele at each of the 15 enzyme loci. 
This study has demonstrated that $S$. byodysenteriae is genetically diverse, and that a relatively high level of recombination has shaped the overall population structure of the species. It is possible that similar mechanisms operating in the genus Serpulina may be responsible for the high rate of recombination in both $S$. hyodysenteriae and S. pilosicoli. A non-lytic bacteriophage capable of transducing $S$. byodysenteriae DNA from one strain to another is a likely candidate (Humphrey et al., 1997), but further research should also investigate other possible means of genetic transfer and recombination. The epidemic population structure of $S$. byodysenteriae suggests that certain clones may be more virulent or have better survival mechanisms than others, or that the epidemiology of the disease and the measures that have been adopted for the control of SD have limited the opportunity for genetic transfer. The practical implications of a recombinant population structure in relation to the epidemiology, host immunity and control of $S$. byodysenteriae require further investigation.

\section{ACKNOWLEDGEMENTS}

This work was supported by a grant from the Australian Pig Research and Development Corporation (PRDC). D. J. T. was in receipt of a PRDC Postgraduate Scholarship. We sincerely thank Drs Neil Jensen, Agnes ter Huurne, Richard Sellwood, Thad Stanton and Jaeil Lee for the provision of non-Australian isolates used in this study. We also thank Camilla Maltas and Julie Ardley for technical assistance.

\section{REFERENCES}

Atyeo, R. F., Trott, D. J. \& Hampson, D. J. (1996a). Use of polymerase chain reaction for the detection of swine dysentery and intestinal spirochaetosis from faecal samples. In Proceedings of the 14th International Pig Veterinary Society Congress, p. 291. Bologna: University of Bologna.

Atyeo, R. F., Trott, D. J., Robertson, I. D., Buddle, J. R. \& Hampson, D. J. (1996b). Epidemiological analysis of Serpulina pilosicoli within a high-health status pig herd. In Proceedings of the 14th International Pig Veterinary Society Congress, p. 287. Bologna: University of Bologna.

Baranton, G. \& Old, I. G. (1995). The spirochetes: a different way of life. Bull Inst Pasteur 93, 63-95.

Baum, D. H. \& Joens, L. A. (1979). Serotypes of beta-hemolytic Treponema hyodysenteriae. Infect Immun 25, 792-796.

Burr, E. J. (1968). Division sorting with mixed character types. I. Standardisation of character values. Aust Comput J 1, 97-99.

Burr, E. J. (1970). Division sorting with mixed character types. II. Fusion strategies. Aust Comput J 2, 98-103.

Burrows, M. R. \& Lemcke, R. M. (1981). Identification of Treponema byodysenteriae by a rapid slide agglutination test. Vet Rec 108, 187-189.

Combs, B., Hampson, D. J., Mhoma, J. R. L. \& Buddle, J. R. (1989). Typing of Treponema byodysenteriae by restriction endonuclease analysis. Vet Microbiol 19, 351-359.

Combs, B. G., Hampson, D. J. \& Harders, S. J. (1992). Typing of Australian isolates of Treponema byodysenteriae by serology and by DNA restriction endonuclease analysis. Vet Microbiol 31, 273-285.

Cutler, R. \& Gardner, I. (1988). A Blueprint for Pig Health
Research, pp. 48-49. Canberra: Australian Pig Research Council. Dugourd, D., Jacques, M., Bigras-Poulin, M. \& Harel, J. (1996). Characterization of Serpulina hyodysenteriae isolates of serotypes 8 and 9 by random amplification of polymorphic DNA analysis. Vet Microbiol 48, 305-314.

Fernie, D. S., Ripley, P. H. \& Walker, P. D. (1983). Swine dysentery: protection against experimental challenge following single dose parenteral immunization with inactivated Treponema byodysenteriae. Res Vet Sci 35, 217-221.

Fusté, M. C., Pineda, M. A., Palomar, J., Vinas, M. \& Lorén, J. G. (1996). Clonality of multidrug-resistant nontypable strains of Haemophilus influenzae. J Clin Microbiol 34, 2760-2765.

Go, M. F., Kapur, V., Graham, D. Y. \& Musser, J. M. (1996). Population genetic analysis of Helicobacter pylori by multilocus enzyme electrophoresis: extensive allelic diversity and recombinational population structure. J Bacteriol 178, 3934-3938.

Hampson, D. J., Mhoma, J. R. L., Combs, B. \& Buddle, J. R. (1989). Proposed revisions to the serological typing system for Treponema hyodysenteriae. Epidemiol Infect 102, 75-84.

Hampson, D. J., Maltas, C. D., Stephens, C. P., McKechnie, K. \& Buller, N. B. (1994). Serogroups of Australian isolates of Serpulina byodysenteriae. Aust Vet J 71, 347.

Hampson, D. J., Atyeo, R. F. \& Combs, B. G. (1997). Swine dysentery. In Intestinal Spirochaetes in Domestic Animals and Humans, pp. 175-209. Edited by D. J. Hampson \& T. B. Stanton. Wallingford: CAB International.

Harel, J., Belanger, M., Forget, C. \& Jacques, M. (1994). Characterisation of Serpulina hyodysenteriae isolates of serotypes 8 and 9 from Quebec by restriction endonuclease fingerprinting and ribotyping. Can J Vet Res 58, 302-305.

Hookey, J. V., Barrett, S. P., Reed, C. S. \& Barber, P. (1994). Phylogeny of human intestinal spirochaetes inferred from $16 \mathrm{~S}$ rDNA sequence comparisons. FEMS Microbiol Lett 117, 345-350.

Humphrey, S. B., Stanton, T. B. \& Jensen, N. S. (1995). Mitomycin $\mathrm{C}$ induction of bacteriophages from Serpulina hyodysenteriae and Serpulina innocens. FEMS Microbiol Lett 134, 97-101.

Humphrey, S. B., Stanton, T. B., Jensen, N. S. \& Zuerner, R. L. (1997). Purification and characterization of VSH-1, a generalized transducing bacteriophage of Serpulina byodysenteriae. J Bacteriol 179, 323-329.

ter Huurne, A. A. H. M. \& Gaastra, W. (1995). Swine dysentery: more unknown than known. Vet Microbiol 46, 347-360.

ter Huurne, A. H. M., van Houten, M., Koopman, M. B. H., van der Zeijst, B. A. M. \& Gaastra, W. (1992a). Characterization of Dutch porcine Serpulina (Treponema) isolates by restriction endonuclease analysis and DNA hybridization. J Gen Microbiol 138, 1929-1934.

ter Huurne, A. A. H. M., van Houten, M., Muir, S., Kusters, J. G., van der Zeijst, B. A. M. \& Gaastra, W. (1992b). Inactivation of a Serpula (Treponema) byodysenteriae haemolysin gene by homologous recombination: importance of this haemolysin in the pathogenesis of $S$. byodysenteriae in mice. FEMS Microbiol Lett 92, 109-114.

Hyatt, D. R., ter Huurne, A. A. H. M., van der Ziejst, B. A. M. \& Joens, L. A. (1994). Reduced virulence of Serpulina hyodysenteriae haemolysin-negative mutants in pigs and their potential to protect pigs against challenge with a virulent strain. Infect Immun 62, 2244-2248.

Jensen, N. S. \& Stanton, T. B. (1993). Comparison of Serpulina byodysenteriae B78, the type strain of the species, with other $S$. byodysenteriae strains using enteropathogenicity studies and 
restriction fragment length polymorphism analysis. Vet Microbiol 36, 221-231.

Jensen, N. S., Stanton, T. B. \& Swayne, D. E. (1996). Identification of the swine pathogen Serpulina byodysenteriae in rheas ( $R$ hea americana). Vet Microbiol 52, 259-269.

Joens, L. A. \& Glock, R. D. (1979). Experimental infection in mice with Treponema byodysenteriae. Infect Immun 25, 757-760.

Joens, L. A., Songer, J. G., Harris, D. L. \& Glock, R. D. (1978). Experimental infection with Treponema byodysenteriae in guinea pigs. Infect Immun 22, 132-135.

Joens, L. A., Whipp, S. C., Glock, R. D. \& Nuessen, M. E. (1983). Serotype-specific protection against Treponema byodysenteriae infection in ligated colonic loops of pigs recovered from swine dysentery. Infect Immun 39, 460-462.

Kapur, V., Sischo, W. M., Greer, R. S., Whittam, T. S. \& Musser, J. M. (1995). Molecular population genetic analysis of Stapbylococcus aureus recovered from cows. J Clin Microbiol 33, 376-380.

Kunkle, R. A., Harris, D. L. \& Kinyon, J. M. (1986). Autoclaved liquid medium for propagation of Treponema hyodysenteriae. $J$ Clin Microbiol 24, 669-671.

Lau, T. T. A. \& Hampson, D. J. (1992). The serological grouping system for Serpulina (Treponema) hyodysenteriae. Epidemiol Infect 109, 255-263.

Lee, J. I. \& Hampson, D. J. (1994). Genetic characterisation of intestinal spirochaetes and their association with disease. $J$ Med Microbiol 40, 365-371.

Lee, J. I., Hampson, D. J., Combs, B. G. \& Lymbery, A. J. (1993a). Genetic relationships between isolates of Serpulina (Treponema) byodysenteriae, and comparison of methods for their subspecific differentiation. Vet Microbiol 34, 35-46.

Lee, J. I., Hampson, D. J., Lymbery, A. J. \& Harders, S. J. (1993b). The porcine intestinal spirochaetes: identification of new genetic groups. Vet Microbiol 34, 273-285.

Lee, J. I., McLaren, A. J., Lymbery, A. J. \& Hampson, D. J. (1993c). Human intestinal spirochetes are distinct from Serpulina byodysenteriae. J Clin Microbiol 31, 16-21.

Lymbery, A. J., Hampson, D. J., Hopkins, R. M., Combs, B. \& Mhoma, J. R. L. (1990). Multilocus enzyme electrophoresis for identification and typing of Treponema hyodysenteriae and related spirochaetes. Vet Microbiol 22, 89-99.

Lysons, R. J., Burrows, M. R., Jones, P. W. \& Collins, P. (1987). Swine dysentery, a new and effective vaccine. Pig Vet Soc Proc 18, 87-91.

Maiden, M. C. J. \& Feavers, I. M. (1995). Population genetics and global epidemiology of the human pathogen Neisseria meningitidis. In Population Genetics of Bacteria, pp. 269-293. Edited by S. Baumberg, J. P. W. Young, E. M. H. Wellington \& J. R. Saunders. Cambridge: Cambridge University Press.

Maynard Smith, J., Smith, N. H., O'Rourke, M. \& Spratt, B. G. (1993). How clonal are bacteria? Proc Natl Acad Sci USA 90, 4384-4388.

Milner, J. A. \& Sellwood, R. (1994). Chemotactic response to mucin by Serpulina byodysenteriae and other porcine spirochetes: potential role in intestinal colonization. Infect Immun 62, 4095-4099.

Nei, M. (1977). F-statistics and analysis of gene diversity in subdivided populations. Ann Hum Genet 41, 225-233.

Pettersson, B., Fellström, C., Andersson, A., Uhlén, M., Gunnarsson, A. \& Johansson, K. (1996). The phylogeny of intestinal porcine spirochetes (Serpulina species) based on sequence analysis of the $16 \mathrm{~S}$ rRNA gene. J Bacteriol 178, 4189-4199.

Rosey, E. L., Kennedy, M. J., Petrella, D. K., Ulrich, R. G. \& Yancey, R. J., Jr (1995). Inactivation of Serpulina hyodysenteriae flaA1 and flaB1 periplasmic flagellar genes by electroporation-mediated allelic exchange. J Bacteriol 177, 5959-5970.

Selander, R. K., Caugant, D. A., Ochman, H., Musser, J. M., Gilmour, M. N. \& Whittam, T. S. (1986). Methods of multilocus enzyme electrophoresis for bacterial population genetics and systematics. Appl Environ Microbiol 51, 873-884.

Stanton, T. B. (1992). Proposal to change the genus designation Serpula to Serpulina gen. nov. containing the species Serpulina byodysenteriae comb. nov. and Serpulina innocens comb. nov. Int J Syst Bacteriol 42, 189-192.

Stanton, T. B. (1997). Physiology of ruminal and intestinal spirochaetes. In Intestinal Spirochaetes in Domestic Animals and Humans, pp. 7-45. Edited by D. J. Hampson \& T. B. Stanton. Wallingford: $\mathrm{CAB}$ International.

Stanton, T. B., Lee, J. I., McLaren, A. J., Trott, D. J., Hampson, D. J. \& Paster, B. J. (1996). Differentiation of intestinal spirochaetes by multilocus enzyme electrophoresis and $16 \mathrm{~S}$ rRNA sequence comparisons. FEMS Microbiol Lett 136, 181-186.

Stanton, T. B., Jensen, N. S., Bosworth, B. T. \& Kunkle, R. A. (1997). Evaluation of the virulence of rhea $S$. byodysenteriae strains for swine. In Proceedings of the 1st National Animal Disease Centre Virtual Conference, p. 100006. Ames, IA.

Sueyoshi, M. \& Adachi, Y. (1990). Diarrhoea induced by Treponema byodysenteriae: a young chick caecal model for swine dysentery. Infect Immun 58, 3348-3362.

Taylor, D. J. \& Trott, D. J. (1997). Porcine intestinal spirochaetosis and spirochaetal colitis. In Intestinal Spirochaetes in Domestic Animals and Humans, pp. 211-241. Edited by D. J. Hampson \& T. B. Stanton. Wallingford: CAB International.

Trott, D. J., Atyeo, R. F., Lee, J. I., Swayne, D. A., Stoutenburg, J. W. \& Hampson, D. J. (1996). Genetic relatedness amongst intestinal spirochaetes isolated from rats and birds. Lett Appl Microbiol 23, 431-436.

Woese, C. R. (1987). Bacterial evolution. Microbiol Rev 51, 221-271.

Zuerner, R. L. \& Stanton, T. B. (1994). Physical and genetic map of the Serpulina byodysenteriae B78 chromosome. J Bacteriol 176, 1087-1092.

Received 15 May 1997; revised 4 July 1997; accepted 9 July 1997. 